\title{
Congresso Médico Universitário - Uma Perspectiva Histórica
}

\author{
Luiz Fernando Ferraz da Silva
}

INTRODUÇÃO

$\mathrm{N}_{\mathrm{da}}^{\mathrm{o}}$ ano em que a Faculdade de Medicina da USP completa o seu centenário, faz aniversário redondo também o seu Congresso Médico Universitário, organizado pelo Departamento Científico e que em 2012 completa sua terceira década. Estes 30 anos podem ser analisados por diferentes prismas como a formação acadêmica, o desafio organizacional, a interação acadêmica e o incentivo e valorização da produção científica dos acadêmicos. A análise desta história permite não apenas reconhecer a evolução observada continuamente pelo COMU, mas também o esforço e dedicação do Departamento Científico e de seus componentes para torná-lo não apenas uma realidade anual, mas para integrá-lo de forma substancial ao calendário acadêmico da Faculdade de Medicina da USP e buscar a necessária inovação e superação esperadas da instituição centenária que o sedia.

\section{ASPECTOS HISTÓRICOS}

A semente do que viria a ser o COMU surge em 1940 quando o então presidente do Departamento Científico, o acadêmico Carlos da Silva Lacaz, sexto anista da Faculdade de Medicina da USP organizou o I Congresso dos Estudantes de Medicina. Já durante os anos 40 e 50 aconteceram as Semanas Brasileiras de Debates Científicos, sediadas anualmente por diferentes instituições em várias regiões do Brasil como Minas Gerais, Bahia, Pernambuco e Paraná. Nestes eventos destacavam-se as discussões de trabalhos científicos realizados por acadêmicos e professores. No ano de 1954 a FMUSP sedia pela primeira vez a Semana Brasileira de Debates Científicos, congregando em 6 dias (1 a 8 de agosto de 1954) produtivas discussões científicas. Estas semanas foram não apenas inspiradoras para a posterior criação do COMU, como foram reavivadas e aprimoradas através das diversas atividades científicas programadas nos Congressos subsequentes.

No início da década de 1980 algumas escolas médicas do país já realizavam congressos próprios no Brasil como a Faculdade de Medicina da Bahia (UFBA) e do Rio de Janeiro (UFRJ). Inspirados nestas iniciativas e nos excelentes resultados das semanas científicas, este processo de gestação e criação levou cerca de 2 anos e foi capitaneado pelo acadêmico Paulo Manuel Pego Fernandes. Detalhes deste processo são mais rica e realisticamente narrado pelo próprio em artigo que compõe esta mesma edição da Revista de Medicina, motivo pelo qual este artigo restringe-se a mencionar que o mesmo ocorreu de 31 de maio a 5 de junho de 1982 e contou com cursos, palestras e apresentação de trabalhos científicos.

Nos 30 anos seguintes diretorias subsequentes do Departamento Científico empenharam-se em aprimorar e aprofundar a experiência vivida pelos acadêmicos durante os diversos eventos do COMU em suas mais diferentes vertentes.

\section{Formação acadêmica}

Ao considerar o papel de eventos formativos no

Formado pela Faculdade de Medicina da USP em 2002 é atualmente professor do Departamento de Patologia da FMUSP, foi colaborador do XVII COMU, membro da comissão organizadora do XVIII COMU e Coordenador Geral do XIX COMU. 
contexto de um congresso acadêmicos dois fatores devem ser considerados: (1) a evolução científica e tecnológica iniciada no século $X X$ fez com que o conhecimento médico se tornasse cada vez mais amplo e aprofundado. Ao mesmo tempo, o curso médico, apesar de agregar progressivamente novos conhecimentos e disciplinas, ele não sofreu grandes alterações em termos de duração, o que faz com que alguns tópicos sejam abordados de forma mais superficial durante o curso médico regular; (2) as bases curriculares do curso médico no Brasil, nos seus anos iniciais, contam com uma carga horária reduzida de disciplinas com forte conteúdo clínico ou a eles integrada, priorizando as disciplinas básicas, 0 que tem uma explicação estrutural coerente, porém deixa no acadêmico um sentimento de distanciamento com a realidade do conhecimento e prática médica propriamente ditas.

Desta forma é fácil compreender por que deste sua primeira edição, o COMU incorporou atividades formativas buscando a complementação e aprofundamento de alguns temas de interesse dos alunos, que pro sua aplicabilidade prática, quer pela superficialidade com que é abordada nas disciplinas regulares.

A forma como este processo vem sendo abordado sofreu variações desde a primeira edição do COMU que contava basicamente com cursos em módulos e palestras de profissionais renomados em suas respectivas áreas, buscando o desenvolvimento de conhecimentos relevantes. Com o passar do tempo outras estratégias foram utilizadas como por exemplo a discussão de casos relevantes (ainda nas primeiras edições).

A progressiva valorização do desenvolvimento estruturado de habilidades e atitudes (em adição à aquisição de conhecimentos) aliado à reestruturação da FMUSP e à visão das diretorias subsequentes do Departamento Científico levou, em 2005 à incorporação definitiva de Workshops ao programa do COMU*.

Ao longo deste início de século o mundo vem vivenciado uma grande transformação em termos de globalização, comunicação e dinamismo não apenas da geração mas também do acesso ao conhecimento e à informação. Acompanhando esta realidade cada vez mais prática e objetiva a diretoria do Departamento Científico promove, neste ano festivo, uma reestruturação do processo formativo, buscando agregar novas metodologias para a transmissão do conhecimento utilizando palestras mais curtas tornando o congresso ainda mais dinâmico.

\section{Interação acadêmica}

Um dos pontos mais altos dos congressos médicos em geral é a possibilidade de conhecer e interagir com pessoas com interesses semelhantes. Esta interação é que permite a formação de uma rede de conhecimento e de contatos estratégicos, conhecidos pelo termo em inglês "networking". Esta rede de relacionamentos pode ser concebida em termos científicos, para estimular o desenvolvimento de trabalhos em cooperação; ou em termos formativos, para discussão de processos e metodologias de aprendizagem, da troca entre diferentes formas de aprender e entre diferentes currículos.

No COMU este processo é intenso desde sua criação. Com a participação de acadêmicos de medicina de diferentes escolas e locais do país, acadêmicos de cursos de outras áreas da saúde e profissionais e professores de diferentes disciplinas, 0 Congresso torna-se um excelente ponto de encontro e convergência, possibilitando ao acadêmico vivenciar a pluralidade destes eventos e criar o seu próprio "networking" a partir de suas prioridades e afinidades.

\section{Valorização da produção científica dos acadêmicos}

Este é, sem dúvida, um ponto alto do Congresso Médico Universitário. Como anteriormente citado, eventos científicos prévios fizeram parte do embrião do COMU, que já na sua primeira edição trouxe a temática científica para dentro do Congresso.

$\mathrm{Na}$ área médica em geral e na Faculdade de Medicina da USP em especial, a pesquisa científica é muito estimulada e valorizada desde o início do curso de graduação. O COMU foi o primeiro evento dedicado à apresentação de trabalhos científicos primariamente produzidos por acadêmicos no contexto da Faculdade de Medicina. Apenas para efeito comparativo, o Simpósio Internacional de Iniciação Científica da USP (SIICUSP), atualmente o maior evento de apresentação de trabalhos científicos produzidos essencialmente por graduandos do país, foi criado 11 anos depois do COMU, que nesta época contava, não apenas com a apresentação de trabalhos, mas também com a premiação dos

\footnotetext{
* Embora o primeiro Workshop do COMU tenha acontecido em 1995 na sua edição XIV, foi a partir do XXIV COMU em 2005 que eles se tornaram regulares e com formato estruturado.
} 
mesmos, tornando-se assim uma forma adicional de incentivo à produção científica dos graduandos.

Neste processo de valorização estes prêmios tiveram grande importância desde a criação do COMU. Já na primeira edição o Congresso contou com o I Prêmio Oswaldo Cruz (POC) que evoluiu ao longo dos anos, chegando a premiar seis áreas: Básica, Clínica, Cirúrgica, Medicina Preventiva, Ensino Médico e Relato de Caso. Atualmente o POC mantém a mesma estrutura, com exceção da área de Ensino Médico que foi retirada em 2001, uma vez que o perfil de concorrência destoava muito do restante das áreas do Prêmio.

O POC recebe anualmente inscrições de trabaIhos que são julgados por comissões independentes compostas por professores e médicos em relação aos méritos científicos e à apresentação oral dos trabalhos em duas fases.

Em 1995, foi adicionado ao repertório do COMU o Prêmio Monografias, estimulando não apenas a produção científica original, mas o estudo sistematizado de temas relevantes do conhecimento médico. Em menos de cinco anos o número de monografias submetidas ao Congresso mais que triplicou. O formato de julgamento também foi desenvolvido de forma semelhante ao aplicado ao POC.

O aumento progressivo do número de trabalhos submetidos ao COMU, e o formato de apresentação nos prêmios de certa forma limitava o número de trabalhos efetivamente apresentados, frente aos submetidos, uma vez que apenas um número limitado podia ser encaixado na programação de apresentação oral. Entendendo esta situação a relevância de dar a oportunidade para a apresentação dos trabalhos dos alunos foi criada em 1997 no XVI COMU a sessão de painéis, que possibilitava a apresentação não só de trabalhos científicos originais, mas também o relato de experiências vividas em atividades de extensão como ligas acadêmicas. O COMU chegou a contar anualmente com mais de 100 painéis apresentados nos corredores da Faculdade de Medicina da USP durante sua realização. Durante 9 anos a Sessão de Painéis continuou com esta configuração. Em 2006 foi instituída também uma premiação para os melhores painéis, inicialmente em uma única categoria geral e posteriormente, a partir de 2007, em cinco categorias a saber: básica, clínica, cirúrgica, liga acadêmica e relato de caso, como permanece até hoje.

\section{Desafio organizacional}

Ao mesmo tempo em que todos os participantes se beneficiam dos aspectos formativos e científicos do COMU, um grupo mais restrito de pessoas tem a oportunidade de um aprendizado adicional. A diretoria do Departamento Científico tem, anualmente, um grande desafio que é o de aprender a montar um evento do porte do COMU em todas as suas facetas e fazê-lo acontecer.

Este processo envolve um grande trabalho em equipe com organização e dedicação, além de envolver um grande aprendizado que vai desde estratégias de captação de recursos, busca de patrocínios e gerenciamento financeiro, passando por elementos estratégicos como definição da programação formativa e científica, até aspectos mais operacionais como divulgação e gerenciamento local do evento como um todo.

A diretoria também conta com o apoio de colaboradores, outros alunos da Faculdade que embora não façam parte da diretoria, desempenham funções voluntárias específicas no processo de preparação e organização do COMU.

Este processo sem dúvida contribui para a formação do aluno uma vez que possibilita a ele uma nova forma de aprendizado e, em algum grau, conhecimentos sobre gestão de projetos e eventos, que são extremamente úteis na vida prática do médico, seja ele um pesquisador, um assistencialista com predomínio de atividades ambulatoriais ou hospitalares, ou ambos.

\section{Impressões pessoais}

Tive o privilégio de participar do XVII COMU (1998) e do XVIII COMU (1999) como colaborador e liderar diversos processos do XIX COMU (2000), além de participar como acadêmico dos COMUs de 1997, 2001 e 2002. Após minha formação pude ainda participar ministrando módulos especiais (patologia/discussão de autópsias) e como avaliador de trabalhos dos diferentes prêmios do COMU.

Tendo acompanhado a história do Congresso nos últimos 15 anos e observando tudo o que vivenciei neles percebo o quanto foram importantes na minha formação, não apenas no processo de aquisição de conhecimento, como na formação do meu "networking" interno na Faculdade, do desenvolvimento de alguma capacidade organizacional que foi muito importante em outros momentos da minha vida acadêmica. Pude perceber também o quanto os prêmios científicos são relevantes para estimular o aluno a persistir e reconhecer a importância da geração do conhecimento. Tenho percebido que a qualidade das atividades e dos trabalhos apresentados vem sendo aprimorada a cada ano o que reflete a preocupação constante tanto dos organizadores como dos participantes em fazer a cada ano um evento melhor. 


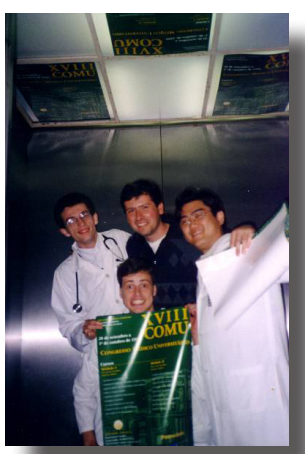

Figura 1. Preparativos/divulgação do XVIII COMU nos elevadores da FMUSP
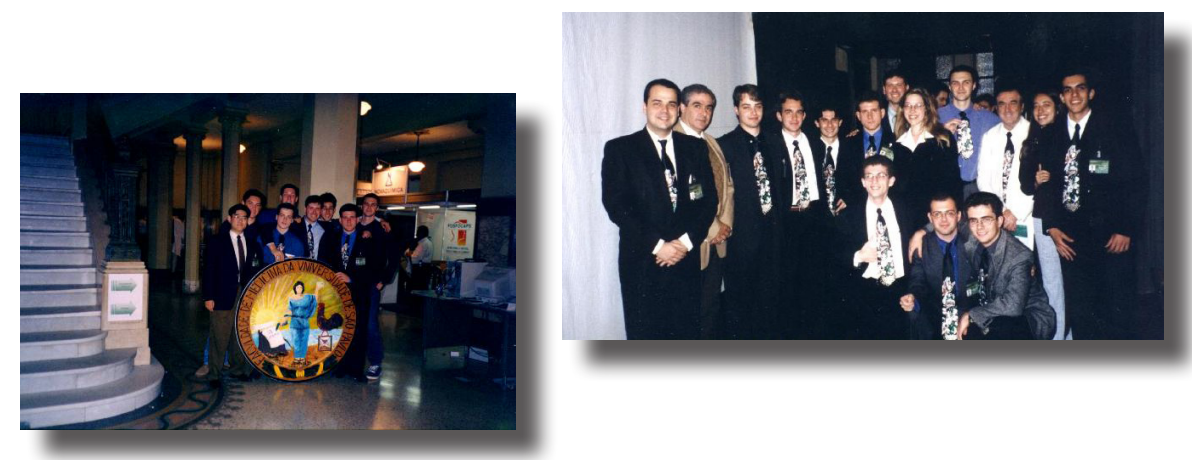

Figuras 2 e 3. Comissão organizadora do XVIII COMU

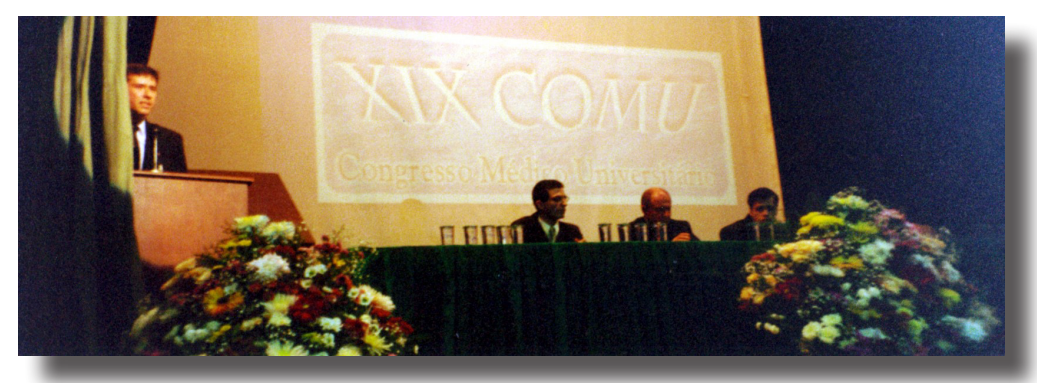

Figura 4. Cerimonia de abertura do XIX COMU no teatro da FMUSP

\section{CONSIDERAÇÕES FINAIS}

Considerando os aspectos anteriormente destacados, ficam claros os motivos que fizeram com que o COMU chegasse aos seus trinta anos com uma aparência extremamente jovem. Aliando (1) atividades formativas e científicas de qualidade crescente; (2) estímulo à participação efetiva de acadêmicos e profissionais; e (3) ousadia no que tange à incorporação de modernas metodologias e ferramentas de apresentação, o COMU consegue aliar sua tradição e competência a um irresistível ar de avanço e modernidade. Trata-se portanto de um evento digno de uma instituição centenária que procura se reconstruir e avançar a cada dia.

\section{REFERÊNCIAS}

1. Lacaz CS. Faculdade de medicina: reminiscência, tradição, memória de minha escola. São Paulo; 1985.

2. Marinho MGSMC. Trajetória da Faculdade de Medicina da Universidade de São Paulo: aspectos históricos da "Casa de Arnaldo". São Paulo: FMUSP; 2006.

3. Ramalho AS, Vasconcelos LM, Cippiani TM. A história do Congresso Médico Universitário da FMUSP: COMU. Rev Med (São Paulo). 2008;87(3):201-4.

4. Fernandes PMP. Entrevista. Rev Med (São Paulo). 2007;86(1):61-3.

5. Pinotti HW, Gouvêa FP, Ferreira Filho AA, Bacalá L. Reminiscência da Casa de Arnaldo: trajetória de 83 jovens responsáveis, coesos e alegres pela Faculdade de Medicina da Universidade de São Paulo de 1950 a 1955. São Paulo: Edições O.L.M.; 2005.

6. Notas Pessoais do Autor 